\title{
Relationship between lung inflammation, changes in lung function and severity of exposure in victims of the Bhopal tragedy
}

\author{
V.K. Vijayan, K. Sankaran
}

Relationship between lung inflammation, changes in lung function and severity of exposure in victims of the Bhopal tragedy. V.K. Vijayan, K. Sankaran. CERS Journals Ltd 1996.

ABSTRACT: The world's worst chemical industrial disaster, which occurred at Bhopal on 2-3 December, 1984, resulted in considerable respiratory morbidity in the exposed population. Therefore, a study was planned to evaluate the relationship between lower respiratory tract inflammation, lung function and severity of exposure.

Sixty patients exposed to methyl isocyanate and presenting with respiratory symptoms were studied using bronchoalveolar lavage (BAL) 1-7 yrs after the accident. Pulmonary function tests included forced vital capacity (FVC) and forced expiratory volume in one second (FEV1). An index of severity of exposure was derived retrospectively on the basis of the acute symptoms in the victims themselves or the occurrence of death among their family members.

Total lung inflammatory cells $(\mathbf{p}<\mathbf{0 . 0 1})$ and absolute numbers of macrophages $(p=0.01)$ and lymphocytes $(p<0.05)$ increased as severity of exposure increased. FEV1/FVC \% ( $\mathbf{p}=\mathbf{0 . 0 5})$ was also significantly lower as severity of exposure increased. Moderately exposed subjects had significantly lower FEV1/FVC \% $(p<0.05)$ compared to those mildly exposed.

In nonsmokers, BAL neutrophils, both percentage and absolute numbers, showed significant negative correlations with FEV1 \% predicted $\left(r_{s}=-0.350, p<0.05\right.$; and $r_{s}=$ $\mathbf{- 0 . 3 7 4}, \mathbf{p}<\mathbf{0 . 0 1}$, respectively). Neutrophil percentage was negatively correlated with FEV1/FVC \% $\left(r_{\mathrm{s}}=\mathbf{- 0 . 3 7 8} ; \mathrm{p}<0.01\right)$. Absolute lymphocytes had significant negative correlations with FVC $\%$ pred $\left(r_{s}=-\mathbf{0 . 3 1 8} ; p<0.05\right)$. Macrophages had significant positive correlations with FVC $\%$ pred $\left(r_{s}=0.322 ; p<0.05\right)$ and FEV1 \% pred $\left(r_{\mathrm{s}}=0.433 ; \mathrm{p}<0.01\right)$. Radiographic abnormalities (International Labour Organization (ILO) classification) were associated with decline in FEV1\% pred $(\mathbf{p}<0.05)$.

This study suggests that pulmonary function abnormalities occur in gas-exposed subjects as a consequence of an abnormal accumulation of lung inflammatory cells (lymphocytes and neutrophils), and that the intensity of lung inflammation and reduction in pulmonary function are greater in severely exposed subjects. As it has been observed that decline in pulmonary function is associated with radiographic abnormalities, there is a suggestion that injury following toxic gas exposure can lead to irreversible lung damage.

Eur Respir J., 1996, 9, 1977-1982.
Cardiopulmonary Medicine Unit, TB Research Centre, Indian Council of Medical Research, Madras, India.

Correspondence: V.K. Vijayan Cardiopulmonary Medicine Unit TB Research Centre

Indian Council of Medical Research Madras 600031 India

Keywords: Bhopal gas disaster bronchoalveolar lavage

fibreoptic bronchoscopy

lung function

lung inflammation

Received: June 61995

Accepted after revision July 51996
Bronchoalveolar lavage (BAL) studies in toxic gas exposed subjects at Bhopal revealed that initial macrophage alveolitis had progressed to macrophage-neutrophilic alveolitis as time passed $[1,2]$. It had also been shown that there was an abnormally elevated fibronectin level in $30 \%$ of subjects exposed to the toxic gas [2]. These findings suggest that the macrophage-neutrophilic alveolitis in toxic gas exposed subjects may cause pulmonary injury and fibrosis, and result in impairment of lung function, as it has been reported that activated lung inflammatory cells, including macrophages, lymphocytes, neutrophils and eosinophils, are capable of releasing toxic mediators and injuring lung parenchyma in various interstitial lung diseases [3]. It is also possible that the intensity of inflammation (alveolitis) will be greater in subjects severely exposed to toxic gas compared to mildly and moderately exposed subjects. As we have previously reported the BAL cell profiles that characterized the lower respiratory tract inflammation in these subjects $[1,2]$, this study evaluates the relationship of cells comprising alveolitis with changes in lung function and severity of exposure in toxic gas victims at Bhopal.

\section{Subjects and methods}

Sixty patients (54 males and 6 females, aged 18-60 yrs) with a history of exposure to toxic gas on 2-3 December, 1984, and presenting with respiratory symptoms 
were included in the study $[1,2]$. The study was carried out 1-7 yrs after the accident. The main presenting symptoms were cough and dyspnoea on exertion. Patients were selected partly from the out-patient clinic exclusively established for toxic gas victims at Hamidia Hospital, Bhopal, and partly from the patients' homes which were visited by VKV. Patients with a previous history of respiratory disease prior to exposure were excluded. Even though a large number of patients were selected for BAL study, only a minority of patients were willing to undergo the procedure. Each individual was evaluated with a detailed history, physical examination, a full plate posteroanterior (PA) chest radiograph, total and differential leucocyte counts in peripheral blood, and a 12-lead electrocardiogram. An experienced chest physician read all chest radiographs using the modified International Labour Organization (ILO) classification [4].

\section{Pulmonary function tests}

Pulmonary function tests, including forced vital capacity (FVC), forced expiratory volume in one second (FEV1) and the ratio of FEV1 to FVC, were carried out using transfer test Model C (PK Morgan Ltd, Chatham, UK). Since the number of patients who had lung volumes and carbon monoxide transfer factor measured in this study was small, these data were not included. FVC and FEV1 were determined from the best two of three acceptable forced vital capacity manoeuvres varying by not more than $\pm 5 \%$ [5]. The largest FVC and FEV1 values corrected for body temperature atmospheric pressure and saturation with water vapour (BTPS) were recorded, even if the two values did not come from the same curve. Pulmonary function results were classified as obstructive and restrictive ventilatory defects using the criteria of Miller et al. [6]. An obstructive ventilatory defect was defined as the FEV1/FVC less than $75 \%$ and FVC more than $75 \%$ predicted. A restrictive ventilatory defect was defined as the FEV1/FVC more than $75 \%$ and FVC less than $75 \%$ pred. Pulmonary function results were compared with the regression equations established for North Indian subjects [7, 8].

\section{Bronchoalveolar lavage}

Bronchoalveolar lavage (BAL) was performed with a flexible fibreoptic bronchoscope as described previously [1], and was carried out in all patients within 3 days following pulmonary function tests. Bronchoscopies and BAL were performed under local anaesthesia. Since there was no radiographic localization of disease in the gas-exposed subjects and there was a possibility that the gas might have entered all lobes of the lung, BAL was performed from three sites. Briefly, five $20 \mathrm{~mL}$ aliquots of normal saline at room temperature were instilled into each lobe and recovered immediately using suction with 50-100 $\mathrm{mmH}_{2} \mathrm{O}$ negative pressure, the bronchoscope being wedged in a subsegmental bronchus of the right middle lobe, lingula and left lower lobe. The fluid was filtered through gauze to remove mucus and was pooled. An aliquot was used for filter preparations. The total number of cells was estimated using a haemocytometer and expressed as cells. $\mathrm{dL}^{-1}$. Filter preparations were made on pooled lavage fluid (uncentrifuged cells) as reported by SALTini et al. [9], and were stained using haematoxylin and eosin stain. A minimum of 400 cells was counted on each slide by two experienced observers (VKV, KS) and recorded independently. Both observers agreed to within $5 \%$ on all lavage analysis and the mean value was used for analysis. BAL were also performed in 17, normal nonsmoking subjects from Madras as controls. Normal subjects from Madras were studied during the same period because of the difficulty in selection and in obtaining consent for BAL from normal subjects from Bhopal. None of these subjects had respiratory symptoms or abnormal physical findings, and all had normal chest radiographs and normal pulmonary function.

\section{Classification of severity of exposure}

As the degree of exposure to the gas may not be the same in all individuals, the patients were categorized into three groups depending upon the severity of exposure. The three categories were as follows:

Severe exposure. If one member of the family had died due to toxic gas exposure or the patient had severe ophthalmic and respiratory symptoms, including unconsciousness on the day of exposure, requiring immediate hospitalization the patient was classified as having had severe exposure.

Moderate exposure. Patients with respiratory and ophthalmic symptoms on the day of exposure requiring only out-patient management were classified as having had moderate exposure.

Mild exposure. Patients with mild respiratory symptoms on the day of exposure, and not seeking immediate medical relief because of mild symptoms, were classified as having had mild exposure.

\section{Statistical analysis}

All data are expressed as mean \pm SD. BAL results in normal subjects and patients were compared using MannWhitney U-test. Pulmonary function results were compared with predicted values using Student's t-test. The relationship between BAL cells and pulmonary function was analysed using Spearman's rank correlation. BAL and pulmonary function results between groups (mild, moderate and severe exposure) were compared using oneway analysis of variance (ANOVA). Tukey's modified t-test (Honestly Significant Difference (HSD) procedure) was also employed to analyse the relationship of exposure class (mild, moderate, severe) with BAL cells and pulmonary function. Stepwise logistic regression was used to determine the relationship between radiographic findings, BAL cell profile and pulmonary function. The relationship between time elapsed since exposure and outcomes (pulmonary function and BAL cells) was analysed using multiple regression. 


\section{Results}

The mean age of the subjects studied was $35 \pm 10 \mathrm{yrs}$ (range 18-60 yrs). The physical characteristics of the study groups are presented in table 1 . BAL was performed 2.8 \pm 1.9 yrs (range $1-7$ years) after exposure. There were six patients with mild exposure, 13 with moderate exposure and 41 with severe exposure. All severely exposed patients were hospitalized immediately after exposure to the toxic gas on 3 December, 1984. All mildly exposed $(n=6)$ and moderately exposed $(n=13)$ subjects were nonsmokers. Ten severely exposed patients were smokers. At the time of the present study, rhonchi and/or rales were heard in 11 patients (severe 8, moderate 3 , mild 0 ). All mildly exposed patients had normal chest radiographs and pulmonary function. Seven of 13 moderately exposed patients had radiographic abnormality of $1 / 0$ or $1 / 1$ (ILO, 1980 classification) [4], and six had obstructive ventilatory defect. Radiographic abnormalities of $1 / 0$ to $2 / 2$ were observed in 29 of 41 severely exposed patients. Eleven had obstructive and eight had restrictive ventilatory defects in the severely exposed group. Overall, the mean FVC (observed vs predicted $3.17 \pm 0.85$ vs $3.7 \pm 0.6 \mathrm{~L} ; \mathrm{p}<0.001$ ) and mean FEV1 (observed $v s$ predicted $2.52 \pm 0.78$ vs $3.0 \pm 0.4 \mathrm{~L} ; \mathrm{p}<0.001$ ) were significantly lower in subjects exposed to toxic gas compared to predicted values $[7,8]$. In control subjects, the mean FVC (observed $v s$ predicted $3.08 \pm 0.59 v s$ $3.16 \pm 0.52 \mathrm{~L} ; \mathrm{p}>0.2$ ) and mean FEV1 (observed $v s$ predicted $2.70 \pm 0.59$ vs $2.81 \pm 0.54 \mathrm{~L} ; \mathrm{p}>0.2$ ) were similar to those of predicted values [10]. Total and differential leucocyte counts in peripheral blood and electrocardiograms were within normal limits in all subjects studied.

As reported previously in these subjects $[1,2]$, severely exposed patients had a significantly elevated total cell count $(\mathrm{p}<0.01)$ in the lower respiratory tract compared to normals and was true whether all individuals or only severely exposed nonsmokers were considered (fig. 1). BAL fluid recoveries were similar in all patient groups (mild $50.1 \pm 9.8 \%$, moderate $49.8 \pm 10.8 \%$ and severe 49.6 $\pm 12.1 \%)$, but were higher in control subjects $(60.7 \%)$. Among the inflammatory and immune effector cells recovered from the lower respiratory tract, there was a significant rise in alveolar macrophages $(\mathrm{p}<0.01)$ and neutrophils $(\mathrm{p}<0.01)$ in severely exposed compared to normal subjects. Similar findings of a significant rise in alveolar macrophages $(\mathrm{p}<0.01)$ and neutrophils $(\mathrm{p}<0.01)$ were seen in severely exposed nonsmokers compared to normal subjects (fig. 1).

\section{Pulmonary function in relation to severity of exposure}

One-way ANOVA of pulmonary function in relation to severity of exposure revealed that $\mathrm{FEV} 1 / \mathrm{FVC} \%$

Table 1. - Physical characteristics of study subjects

\begin{tabular}{lcccc}
\hline & $\mathrm{n}$ & $\begin{array}{c}\text { Age } \\
\text { yrs }\end{array}$ & $\begin{array}{c}\text { Height } \\
\mathrm{cm}\end{array}$ & $\begin{array}{c}\text { Weight } \\
\mathrm{kg}\end{array}$ \\
\hline Mild exposure & 6 & $35 \pm 7$ & $168 \pm 6$ & $51 \pm 6$ \\
Moderate exposure & 13 & $35 \pm 8$ & $166 \pm 9$ & $53 \pm 12$ \\
Severe exposure & 41 & $35 \pm 11$ & $162 \pm 8$ & $52 \pm 9$ \\
\hline All patients & 60 & $35 \pm 10$ & $164 \pm 8$ & $52 \pm 10$ \\
\hline
\end{tabular}

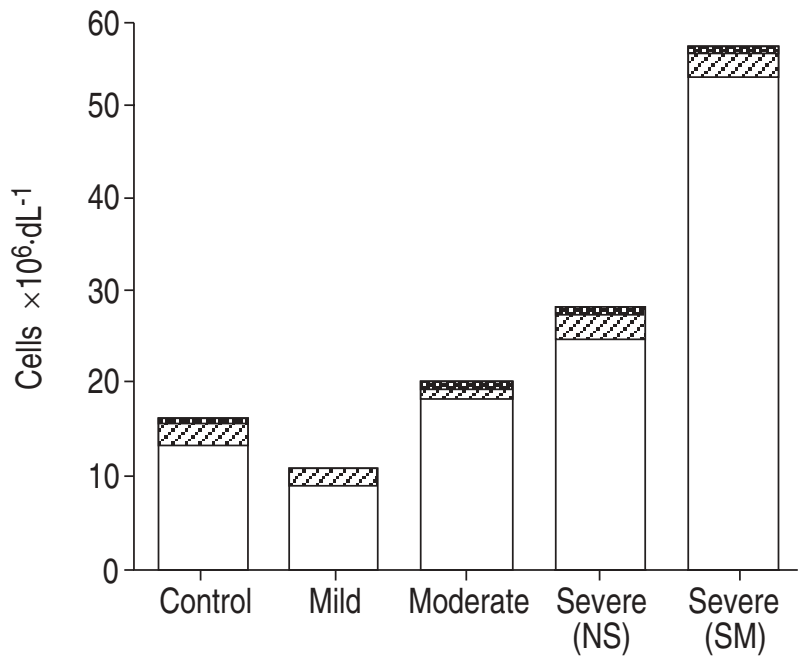

Fig. 1. - BAL findings in relation to severity of exposure. Mann-Whitney U-test: total cells $(\mathrm{p}<0.01)$, macrophages $(\mathrm{p}<0.01)$ and polymorphs $(\mathrm{p}<0.01)$ were significantly higher in severely exposed nonsmokers and smokers compared to control subjects. One-way ANOVA: All subjects: total cells $(\mathrm{p}<0.01)$, macrophages $(\mathrm{p}=0.02)$ and lymphocytes $(\mathrm{p}=0.05)$ increased as severity of exposure increased. Nonsmokers: total cells $(\mathrm{p}<0.01)$, macrophages $(\mathrm{p}=0.01)$ and lymphocytes $(\mathrm{p}<0.05)$ increased as severity of exposure increased. Tukey's modified t-test: severely exposed (all subjects and nonsmokers) had higher total cells $(\mathrm{p}<0.05)$ and macrophages $(\mathrm{p}<0.05)$ compared to mildly exposed subjects. BAL: bronchoalveolar lavage; NS: nonsmoker; SM: smoker; ANOVA: analysis of variance. 瞐㿻 : neutrophils; $\not{Z}$ : lymphocytes; $\square$ : macrophages.

declined significantly $(\mathrm{p}=0.05)$ as severity of exposure increased (fig. 2). FEV1 \% pred showed a declining trend, though it did not attain statistical significance $(\mathrm{p}=0.09) . \mathrm{FEV} 1 / \mathrm{FVC} \%(\mathrm{p}=0.07)$ and $\mathrm{FEV}_{1} \%$ pred $(\mathrm{p}=$ 0.09 ) also showed a declining trend in nonsmokers. Tukey's modified t-test showed that FEV1/FVC \% in mildly exposed subjects was significantly different $(\mathrm{p}<$ 0.05 ) from those moderately exposed. There was no difference in pulmonary function between moderately and

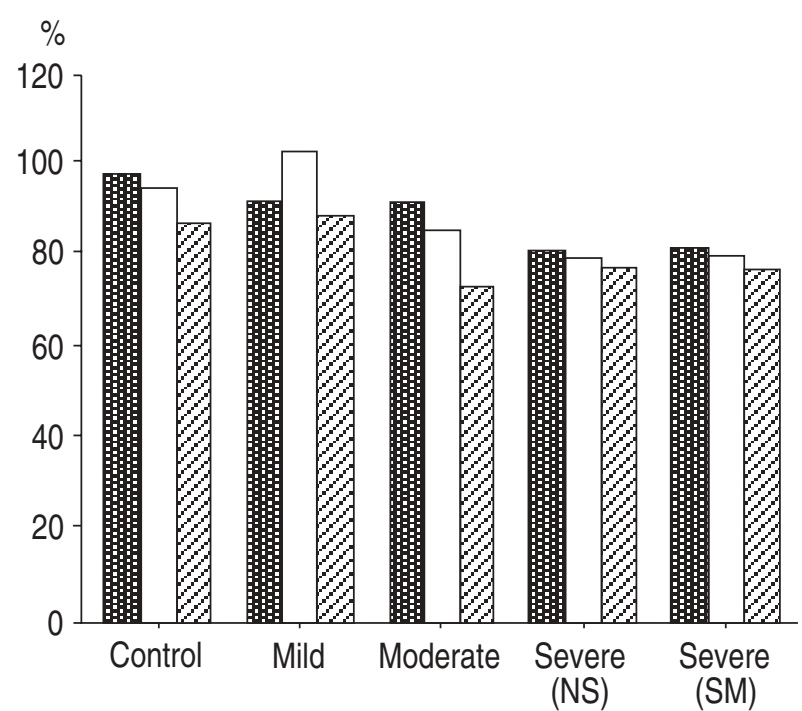

Fig. 2. - Pulmonary function results in relation to severity of exposure. One-way ANOVA: FEV1/FVC \% declined as severity of exposure increased $(\mathrm{p}=0.05)$. $\mathrm{FEV} 1$ : forced expiratory volume in one second; FVC: forced vital capacity; NS: nonsmoker; SM: smoker; ANOVA: analysis of variance. 膭聑 : FVC \% predicted; $\square$ : FEV $1 \%$ predicted; $\quad 22$ : $\mathrm{FEV} 1 / \mathrm{FVC} \%$. 
severely exposed subjects. Seventeen patients (moderate 6 and severe 11) had obstructive ventilatory defect and eight severely exposed had restrictive ventilatory defect.

\section{$B A L$ findings in relation to severity of exposure}

Comparisons of BAL cell differential percentages and absolute counts were made between patients with three grades of severity of exposure. One-way ANOVA demonstrated that total cells $(\mathrm{p}<0.01)$, absolute macrophages $(\mathrm{p}=0.02)$ and absolute lymphocytes $(\mathrm{p}=0.05)$ increased significantly as severity of exposure increased. A similar trend was observed in nonsmokers (total cells, $\mathrm{p}<0.01$; absolute macrophages, $\mathrm{p}=0.01$; absolute lymphocytes, $\mathrm{p}<0.05)$. Tukey's modified t-test revealed that total cells $(\mathrm{p}<0.05)$ and absolute macrophages $(\mathrm{p}<0.05)$ were significantly different in mildly exposed subjects from those in severely exposed subjects (fig. 1). There were no differences in total cells and absolute macrophages between mildly exposed and moderately exposed groups; and between moderately and severely exposed groups. The findings were similar in nonsmokers. The interval between the time of exposure and BAL study was significantly shorter $(\mathrm{p}<0.05)$ in mildly exposed $(1.25 \pm 0.3$ yrs) and severely exposed $(2.77 \pm 1.8 \mathrm{yrs})$ compared to moderately exposed (4.21 \pm 2.2 yrs) subjects (Tukey's modified t-test). In nonsmokers, this interval was significantly shorter in mildly exposed $(\mathrm{p}<0.05)$ compared to moderately and severely exposed $(3.0 \pm 1.8 \mathrm{yrs})$ subjects. There was no difference between moderately and severely exposed nonsmokers.

Correlation of BAL inflammatory cells with pulmonary function (table 2)

The percentage of neutrophils in BAL had a significant negative correlation with FEV1 \% pred and FEV1/ FVC \%. The number of absolute neutrophils in BAL had a significant negative correlation with FVC \% pred and FEV $1 \%$ pred (fig. 3). The number of absolute lymphocytes in BAL had a significant negative correlation with FVC \% pred (fig. 4), and FEV1 \% pred. In nonsmokers, the percentage of neutrophils in BAL had a significant negative correlation with $\mathrm{FEV}_{1} \%$ pred and

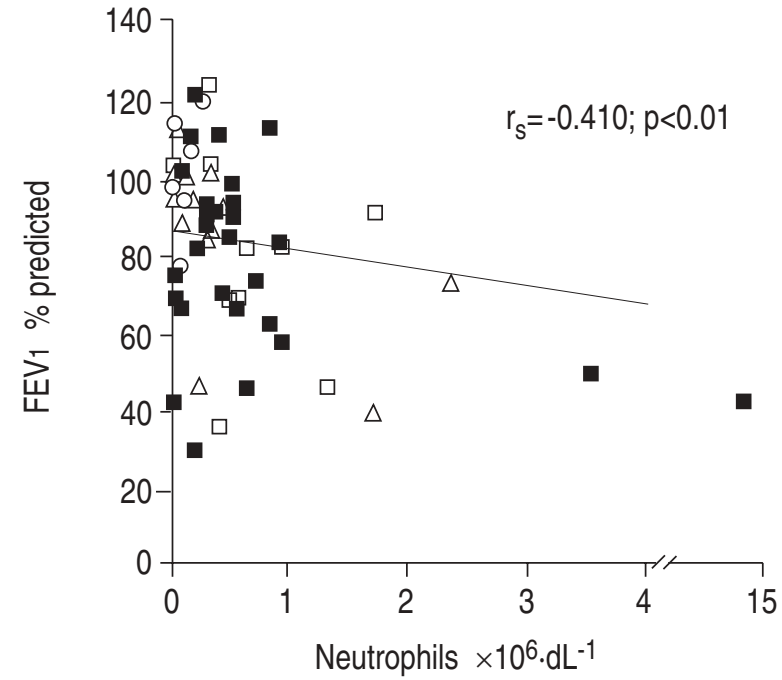

Fig. 3. - Correlation of lung neutrophils with FEV1 \% predicted. 0 : mild exposure; $\Delta$ : moderate exposure; $\mathbf{m}$ : severe exposure (nonsmoker); $\square$ : severe exposure (smoker). FEV 1 : forced expiratory volume in one second. The solid line represents the line of regression.

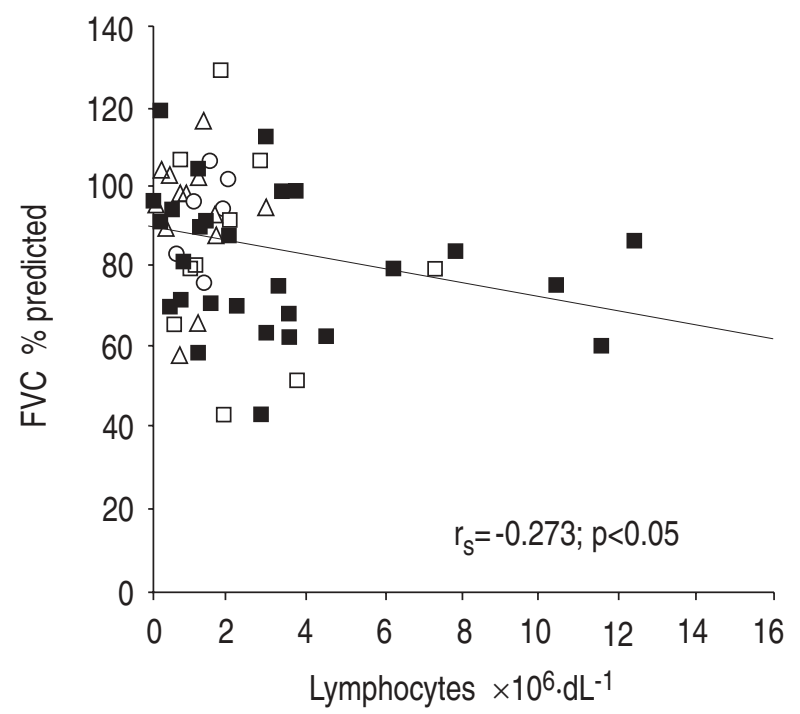

Fig. 4. - Correlation of lung lymphocytes with FVC \% predicted O : mild exposure; $\Delta$ : moderate exposure; $\mathbf{\square}$ : severe exposure (nonsmoker); $\square$ : severe exposure (smoker). FVC: forced vital capacity. The solid line represents the line of regression.

Table 2. - Spearman's rank correlation $\left(r_{s}\right)$ of BAL inflammatory cells with pulmonary function

\begin{tabular}{|c|c|c|c|c|c|c|c|c|c|}
\hline \multirow[t]{2}{*}{ BAL findings } & \multicolumn{3}{|c|}{ FVC $\%$ pred } & \multicolumn{3}{|c|}{ FEV1 $\%$ pred } & \multicolumn{3}{|c|}{ FEV1/FVC } \\
\hline & $\begin{array}{c}\text { All } \\
\text { subjects } \\
(\mathrm{n}=60)\end{array}$ & $\begin{array}{c}\text { Non- } \\
\text { smokers } \\
(\mathrm{n}=50)\end{array}$ & $\begin{array}{c}\text { Smokers } \\
(n=10)\end{array}$ & $\begin{array}{c}\text { All } \\
\text { subjects } \\
(\mathrm{n}=60)\end{array}$ & $\begin{array}{c}\text { Non- } \\
\text { smokers } \\
(\mathrm{n}=50)\end{array}$ & $\begin{array}{c}\text { Smokers } \\
(\mathrm{n}=10)\end{array}$ & $\begin{array}{c}\text { All } \\
\text { subjects } \\
(\mathrm{n}=60)\end{array}$ & $\begin{array}{c}\text { Non- } \\
\text { smokers } \\
(\mathrm{n}=50)\end{array}$ & $\begin{array}{c}\text { Smokers } \\
(\mathrm{n}=10)\end{array}$ \\
\hline Total cells & -0.183 & -0.256 & 0.152 & -0.125 & -0.181 & 0.237 & 0.069 & 0.099 & 0.224 \\
\hline$\underset{\%}{\text { Macrophages }}$ & & $0227 *$ & 0427 & 0150 & $0433 * *$ & 050 & 0066 & 68 & 23 \\
\hline Absolute & $\begin{array}{r}0.121 \\
-0.095\end{array}$ & $\begin{array}{l}0.322^{*} \\
-0.143\end{array}$ & $\begin{array}{l}0.432 \\
0.182\end{array}$ & $\begin{array}{r}0.152 \\
-0.043\end{array}$ & $\begin{array}{l}0.433^{* *} \\
-0.086\end{array}$ & $\begin{array}{l}0.592 \\
0.292\end{array}$ & $\begin{array}{l}0.066 \\
0.096\end{array}$ & $\begin{array}{l}0.268 \\
0.130\end{array}$ & $\begin{array}{l}0.183 \\
0.261\end{array}$ \\
\hline Lymphocytes & & & & & & & & & \\
\hline$\%$ & -0.236 & -0.259 & -0.049 & -0.237 & -0.222 & -0.309 & -0.082 & -0.020 & $-0.689 *$ \\
\hline Absolute & $-0.273 *$ & $-0.318^{*}$ & 0.061 & $-0.258 *$ & -0.258 & -0.201 & -0.051 & 0.026 & -0.657 \\
\hline Neutrophils & & & & & & & & & \\
\hline $\begin{array}{l}\% \\
\text { Absolute }\end{array}$ & -0.158 & -0.083 & -0.540 & $-0.354 * *$ & $-0.350 *$ & -0.409 & $-0.279 *$ & $-0.378 * *$ & 0.295 \\
\hline $\begin{array}{l}\text { Absolute } \\
\text { Eosinophils }\end{array}$ & $-0.296 *$ & -0.205 & -0.627 & $-0.410 * *$ & $-0.374 * *$ & -0.437 & -0.173 & -0.238 & 0.518 \\
\hline$\%$ & -0.024 & 0.044 & -0.202 & -0.181 & -0.150 & -0.046 & -0.216 & -0.233 & 0.370 \\
\hline Absolute & 0.001 & 0.028 & -0.009 & -0.150 & -0.157 & -0.165 & -0.185 & -0.214 & -0.035 \\
\hline
\end{tabular}

BAL: bronchoalveolar lavage; FVC: forced vital capacity; FEV1: forced expiratory volume in one second; \% pred: percentage of predicted value. *: $<0.05 ; * *:<0.01$. 
FEV1/FVC \%. The absolute number of neutrophils in BAL had a significant negative correlation with FEV1 $\%$ pred. The absolute number of lymphocytes had a significant negative correlation with FVC \% pred. The percentage of alveolar macrophages had a significant positive correlation with FVC \% pred, and FEV1 \% pred. Total cell numbers and eosinophils did not have any relationship with pulmonary function.

\section{Relationship of radiographic findings with BAL cells and pulmonary function}

Stepwise logistic regression of radiographic findings with pulmonary function revealed that radiographic abnormalities were associated with reductions in FEV1\% pred $(\mathrm{p}<0.05)$. The relative risk of having radiographic abnormality in persons with abnormal FEV1 ( $<75 \%$ pred) was about five times higher than in those with normal FEV1 (>75\% pred). There is also a suggestion that radiographic abnormalities were associated with an increase in BAL neutrophils $(\mathrm{p}=0.07)$, though it did not attain statistical significance.

When data were analysed using multiple regression, there was no relationship between time elapsed since exposure and the outcome (BAL cells and pulmonary function), except for eosinophils. The r-values for time elapsed since exposure were $0.132(\mathrm{p}>0.2)$ with FEV1/ FVC \%, $0.155(\mathrm{p}>0.2)$ with neutrophils, and 0.300 $(\mathrm{p}=0.02)$ with eosinophils.

\section{Discussion}

The persistence of clinical, radiological and pulmonary function abnormalities, as well as neutrophilic alveolitis and abnormally elevated fibronectin levels in a proportion of subjects suggests the possibility that progressive lung damage could have occurred in subjects exposed to toxic gas at Bhopal [2]. Even though we were not able to measure the quantity of gas inhaled by each subject in order to classify the severity of exposure, the finding of an increase in total lung inflammatory cells recovered by BAL as the severity of exposure increased suggests that the classification adopted in this study was reasonably good. This finding further suggests that intensity of lung inflammation is greater in severely exposed subjects and, hence, the injury resulting from the inflammation and its sequelae will be more pronounced in subjects with severe exposure. This has been further supported by the fact that impairment in pulmonary function was more pronounced in severely exposed subjects.

This study has revealed that pulmonary function measurements, such as FVC \% pred, FEV1 \% pred and FEV1/ FVC $\%$, have significant negative correlations with lower respiratory tract lymphocytes and neutrophils and this finding was independent of smoking habits. Therefore, the considerable respiratory morbidity observed in a group of toxic gas exposed subjects $[11,12]$ may be due to the deleterious effects of lymphocytes and neutrophils on the lung. Therefore, the progression from the macrophagic alveolitis observed in the subacute phase [1] to neutrophilic alveolitis as time passed [2] is an ominous sign. The observation that radiographic abnormalities are associated with decline in pulmonary function and the suggestion that these abnormalities are higher in patients with lung neutrophilia (though not significant) point to the possibility that abnormal accumulation of neutrophils in the lung can result in irreparable lung damage. Similar to our findings in gas exposed victims, Meyer and Zimmerman [13] demonstrated that cystic fibrosis patients with elevated neutrophils in BAL fluid had a lower FEV1, suggesting that the continuous presence of neutrophils contributes to progressive lung damage. The finding of a significant negative correlation of lymphocytes in nonsmokers with dynamic lung volumes (FVC \% pred) in this study may suggest that lymphocytes are associated with lung injury and subsequent decline in pulmonary function, and this is similar to the observation of the association of BAL lymphocytosis with alveolar septal inflammation in patients with idiopathic pulmonary fibrosis [14]. Thus, it is possible that both bronchial and interstitial diseases could occur in patients exposed to toxic gas at Bhopal. We have noticed a relationship between the time elapsed since exposure and eosinophilia. It had been reported previously that BAL eosinophilia in idiopathic pulmonary fibrosis was associated with advanced disease [14], and with a poor response to corticosteroids [15]. Thus, the appearance of lung eosinophilia in gas-exposed subjects as time passes may suggest the possibility of the development of advanced disease and nonresponsiveness to treatment.

It has previously been shown in chronic obstructive pulmonary disease (COPD) that mortality was significantly greater among subjects with obstructive ventilatory defect (patients with lower FEV1/FVC \%, and FEV1 $\%$ pred) $[16,17]$. Therefore, the accumulation of neutrophils in the lung of toxic gas exposed subjects as time passed and its negative correlation with FEV1\% pred and FEV1/FVC \% in this study may suggest the possibility of significant respiratory morbidity and early mortality in subjects exposed to toxic gas, especially in those severely exposed. These findings may further suggest that simple spirometric measurements, such as FVC and FEV1, can be utilized as a marker for objective assessment of respiratory morbidity in gas-exposed subjects. Since lung neutrophilia in these patients is associated with a decline in FEV1, there is also a possibility that a proportion of them may develop hyperreactive airways leading to asthma-like syndrome, as it had been demonstrated that single massive exposure to irritant gases could result in reactive airways dysfunction syndrome [18]. A careful follow-up of the progression of these patients is essential.

In conclusion, this study suggests that the persisting pulmonary function abnormalities in patients exposed to toxic gas at Bhopal may be due to the consequences of an abnormal accumulation of lung inflammatory cells (lymphocytes and neutrophils) and that serious abnormalities of pulmonary function occur in patients who had severe exposure to the gas. There is also a suggestion that the lung damage following toxic gas exposure can be irreversible, as it has been demonstrated that decline in pulmonary function is associated with radiographic abnormalities. 
Acknowledgements: The authors would like to thank the Indian Council of Medical Research, New Delhi, for financial support. They would also like to thank the Madhya Pradesh Government, the Dean, Gandhi Medical College, Bhopal, N.P. Misra (Professor of Medicine) and B.S. Darbari (Professor of Pathology), Gandhi Medical College, Bhopal, for providing the facility at Hamidia Hospital, Bhopal, to conduct this study. Statistical analysis was performed by P. Venkatesan, TB Research Centre, Madras, India.

\section{References}

1. Vijayan VK, Pandey VP, Sankaran K, Mehrotra Y, Darbari BS, Misra NP. Bronchoalveolar lavage study in victims of toxic gas leak at Bhopal. Ind J Med Res 1989; 90: 407-414.

2. Vijayan VK, Sankaran K, Sharma SK, Misra NP. Chronic lung inflammation in victims of toxic gas leak at Bhopal. Respir Med 1995; 89: 105-111.

3. Crystal RG, Bitterman PB, Rennard SI, Hance AJ, Keogh BA. Interstitial lung disease of unknown aetiology: disorders characterised by chronic inflammation of the lower respiratory tract. N Engl J Med 1984; 310: 154-166 and 235-244.

4. Merchant SA, Reger RB. Classification of the chest radiograph for the pneumoconiosis. In: Rom WN et al., eds Environmental and Occupational Medicine. Boston, Little Brown Co., 1983; 113-122.

5. Ferris BG (Ed), Epidemiology standardization project. Am Rev Respir Dis 1978; 118: (Part 2): 62-72.

6. Miller WF, Wu N, Johnson RL. Convenient method of evaluating pulmonary ventilatory functions with a single breath test. Anesthesiology 1956; 17: 480-493.

7. Jain SK, Ramaiah TJ. Spirometric studies in healthy women 15-40 years. Ind J Chest Dis 1967; 9: 1-12.

8. Jain SK, Ramaiah TJ. Normal standards of pulmonary function tests for healthy Indian men 15-40 years old: comparison of different regression equations (prediction formulae). Ind J Med Res 1969; 57: 145-166.

9. Saltini C, Hance AJ, Ferrans VJ, Basset F, Bitterman PB, Crystal RG. Accurate quantification of cells recovered by bronchoalveolar lavage. Am Rev Respir Dis 1984; 130: 650-658.

10. Vijayan VK, Kuppurao KV, Venkatesan P, Sankaran K, Prabhakar R. Pulmonary function in healthy young adult Indians in Madras. Thorax 1990; 45: 611-615.

11. Vijayan VK, Kuppurao KV. Early clinical, pulmonary function and blood gas studies in victims of Bhopal tragedy. Biomedicine 1993; 13: 36-42.

12. Misra NP, Pathak R, Gaur KJBS, et al. Clinical profile of gas leak victims in acute phase after Bhopal episode. Ind J Med Res 1987; 86 (Suppl.): 11-19.

13. Meyer KC, Zimmerman J. Neutrophil mediators, Pseudomonas and pulmonary dysfunction in cystic fibrosis. $J$ Lab Clin Med 1993; 121: 654-661.

14. Watters LC, Schwarz MI, Cherniack RM, et al. Idiopathic pulmonary fibrosis: pretreatment bronchoalveolar lavage cellular constituents and their relationship with lung histopathology and clinical response to therapy. Am Rev Respir Dis 1987; 135: 696-704.

15. Haslam PL, Turton CWG, Lukoszek A, et al. Bronchoalveolar lavage fluid cell counts in cryptogenic fibrosing alveolitis and relation to therapy. Thorax 1980; 35: 328-339.

16. Anthonisen NR. Prognosis in chronic obstructive pulmonary disease: results from multicentre clinical trials. Am Rev Respir Dis 1989; 140: S95-99.

17. Postma DS, Sluiter J. Prognosis of chronic obstructive pulmonary disease: the Dutch Experience. Am Rev Respir Dis 1989; 140: S100-105.

18. Brooks SM, Weiss MA, Bernstein IL Reactive airways dysfunction syndrome (RADS): persistent asthma syndrome after high level irritant exposure. Chest 1985; 88: 376-384. 